\title{
Analysis of Types and Effects of Extensive Disaster - a Case of Tamil Nadu, India
}

\author{
Yaolong Liu ${ }^{1}$, Ye Xue ${ }^{1}$, Huaming Zhang ${ }^{2}$ \\ ${ }^{1}$ College of Economics and Management, Taiyuan University of Technology, Jinzhong 030600, \\ China \\ ${ }^{2}$ Meteorological disaster prevention technology center of Shanxi province, Taiyuan 030002, China

\section{广布型灾害的类型与影响分析一以印度泰米尔 纳德邦为例} \\ 刘耀龙 ${ }^{1}$, 薛晔 ${ }^{1}$, 张华明 ${ }^{2}$ \\ ${ }^{1}$ 太原理工大学 经济管理学院, 晋中 030600 , 中国 \\ ${ }^{2}$ 山西省气象灾害防御技术中心，太原 030002，中国
}

\begin{abstract}
Intensive disaster risk and extensive disaster risk are the two main contemporary trends and patterns of global disaster risk. The former has become the focus of long-term international and academic attention due to its high lethality and destructiveness. The latter shows a local frequency and cumulative effects, gradually attracted the attention of scholars in recent years. For vulnerable groups or areas, extensive disasters are often the main cause of casualties, asset damage and economic loss, and also the culprit of livelihoods, welfare and development. Taking Tamil Nadu in India as an example, this paper analyzes the main types and direct effects of the extensive disasters in this area, and provides a reference for risk assessment of extensive disaster.
\end{abstract}

Keywords: extensive disaster risk; Tamil Nadu; disaster impact

摘要

密集型灾害风险与广布型灾害风险是
当今全球自然灾害风险的两种主要模式, 前者因其高致死性和强破坏性, 成为国际 社会和学术界长期关注的焦点; 后者表现 出的局地频发和累积效应, 近年来逐渐引 起学者们的重视。对于脆弱群体或地区, 广布型灾害往往是人员伤亡、资产破坏和 经济损失的主要致因, 也是影响生计、福 祉和限制发展的罪魁祸首。本文以印度泰 米尔纳德邦为例, 分析该地区广布型灾害 的主要类型和直接影响, 为进一步开展广 布型灾害风险评估提供参考。

关键词: 广布型灾害风险; 泰米尔纳德; 灾害影响

\section{1. 引言}

广布型灾害风险 (Extensive Disaster Risk) 是联合国国际减灾战略 （简称 UNISDR）近年来持续关注的重要灾 害风险情景之一 [1-2]。根据 United Nations 的定义, 广布型灾害风险（也译作 广泛型灾害风险）是指严重程度低、频率 高的危害事件和灾害的风险 [3], 广泛分布 且高度集中于经常发生局部性洪水、山体 滑坡、风暴或干旱的社区。事实上, 与每 一次灾难相邻相随的是数以千计的广布型

E-mail(刘耀龙): liuyaolong@tyut.edu.cn. 
灾害 [4]。正如 UNISDR 所述, 在国际减轻 自然灾害十年实施 25 年和兵库行动框架 实施 10 年后, 全球性的灾害风险并没有 大幅度减少, 而新的风险 (如广布型风险) 积累速度反而超过现有风险的减缓速度 [5]。 显然, 国际社会和学术界对于广布型灾害 风险的认知不足和研究忽视是重要的致因。 藉此, 本文以印度的泰米尔纳德邦 (Tami1 Nadu, India) 为例, 分析该地区广布型灾 害的类型及直接影响, 为系统开展广布型 灾害风险分析与管理提供参考。

\section{2. 研究区域概况}

泰米尔纳德邦, 旧名 “马德拉斯邦”, 为印度 29 个邦之一, 位于印度德干半岛东 南部 (图 1), 总面积为 $130058 \mathrm{~km} 2$, 人口 为 7149.20 万人 (2011 年), 下辖 30 个县、 203 个区, 首府为金奈 (Chennai)。
(965 起, 年均 22.93 起)、韦洛尔县 (T04) 的韦洛尔区 (673 起, 年均 15.30 起)、金 奈县 ( T02) 的金奈区 (600 起, 年均 13.64 起)。灾害记录超过 250 起的区有: 蒂鲁伯蒂县 (T01) 的邦内里区和乌图科泰 区、马杜赖县 (T24) 的马杜赖北区、德尼 县 ( T25) 的贝里耶古勒姆区和乌塔马帕拉 耶姆区以及坎尼亚古马里县 (T30) 的坎儿 古勒姆区 (图 2)。此外, 可瑞什纳吉丽县 (T17) 的克里希纳吉里区和坦加布尔县 (T21) 的阿马佩泰区灾害记录数为 0 。需 要指出的是, 泰米尔纳德邦是 2004 年印度 洋海啸的重灾区, 因此大量的广布型灾害 记录于 2004 和 2005 年。

\section{3. 广布型灾害类型}

按照 GAR 2015 提出的广布型灾害统计 标准 $[5]$, 筛选死亡人数 $<30$ 人, 房屋毁坏

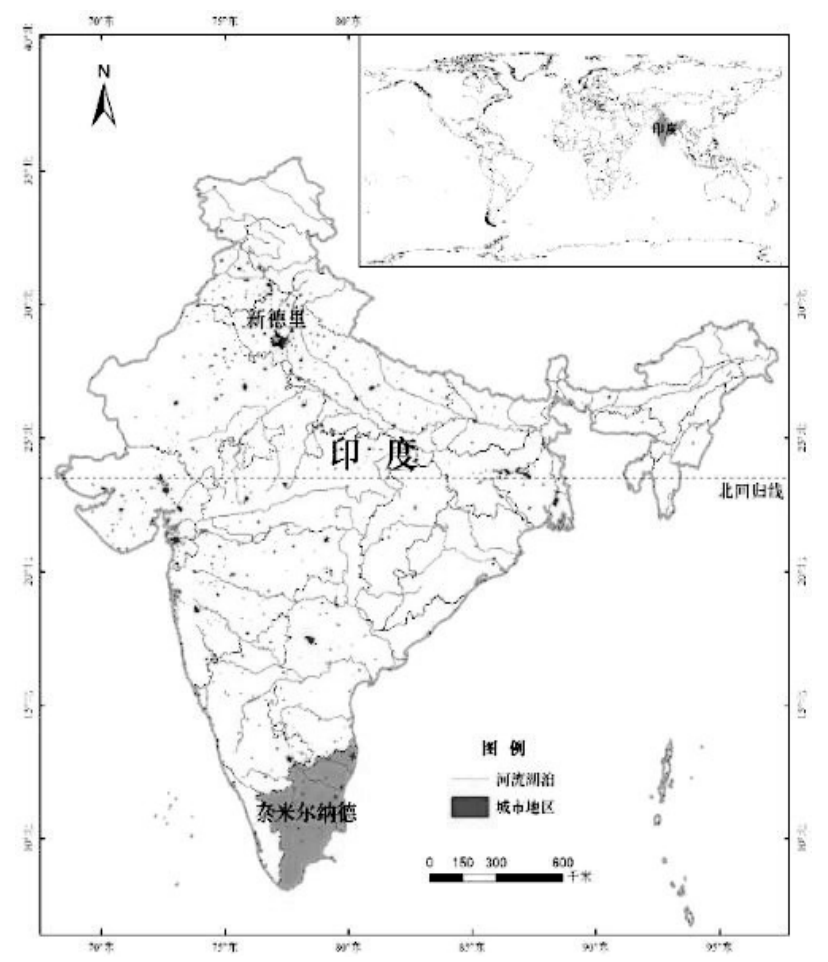

图 1 泰米尔纳德邦的地理位置

1968-2011 年间, 该邦共记录的灾害事 件为 16147 起 (原始数据来源: https://www. desinventar. net/), 主要分 布在古达罗尔县 (T18) 的吉登伯勒姆区
<600 间的灾害事件, 同时, 剔除地震、海 啸、䢐风、火山爆发等密集型灾害, 火灾、 事故、流行病、爆炸、泄露、恐慌、堆积 (事故) 等技术灾害以及部分结构倒塌 


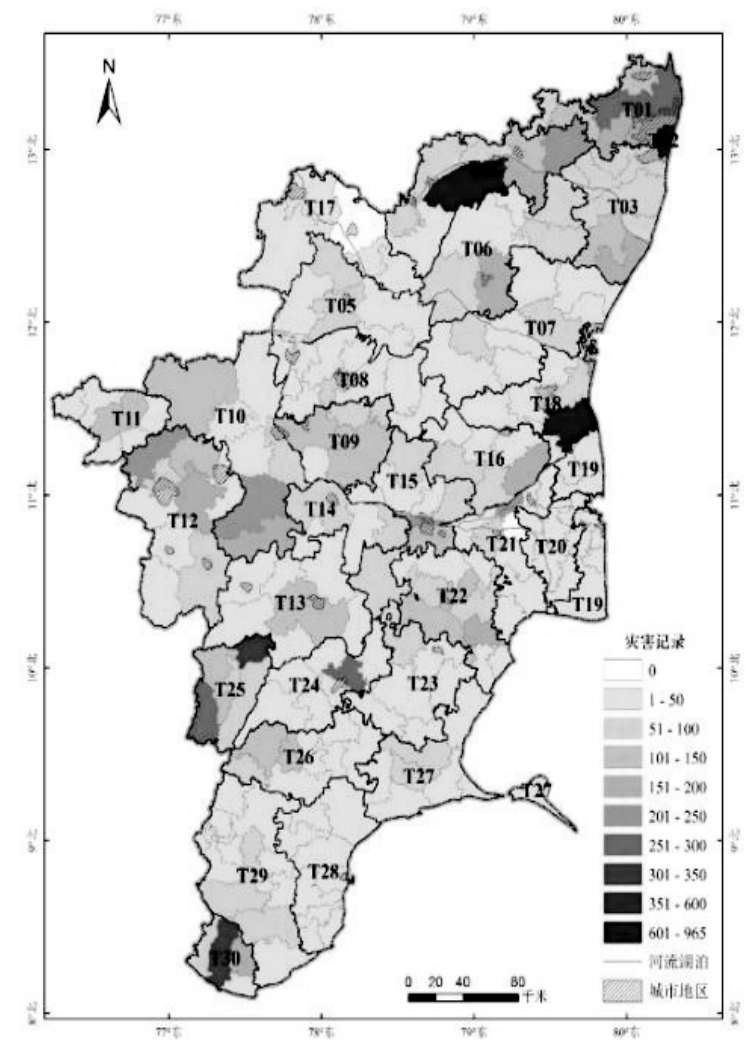

图 2 1968-2011 年泰米尔纳德邦灾害记录

(无成因描述或人为原因) 和其他灾害 (无成因描述或人为原因), 共计获得广布 型灾害记录 8385 条 (原始数据来源同上), 占自然灾害总数的 $98.83 \%$ (表 1), 占全部 灾害记录的 $51.93 \%$ 。

表 1 泰米尔纳德邦的广布型灾害类型与记录

\begin{tabular}{cr|cr|cr}
\hline 类型 & 数量 & 类型 & 数量 & 类型 & 数量 \\
\hline 洪水 & 3152 & 气旋 & 65 & 涌浪 & 4 \\
暴雨 & 3088 & 海啸 & 62 & 雹暴 & 4 \\
森林火灾 & 811 & 山体崩塌 & 42 & 热浪 & 2 \\
闪电 & 307 & 其他 & 21 & 风暴 & 2 \\
电风暴 & 302 & 强风 & 13 & 土壤液化 & 2 \\
干旱 & 237 & 山洪泛滥 & 5 & 冻害 & 1 \\
结构破坏 & 147 & 海水侵蚀 & 4 & 霜 & 1 \\
山洪 & 109 & 潮汐波 & 4 & 总计 & 8385 \\
\hline
\end{tabular}

泰米尔纳德邦的广布型灾害主要为洪 水 $(71.64$ 次/年) 和暴雨 $(70.18$ 次/年), 其次为森林火灾 (18.43 次/年)、闪电 (6.98 次/年)、电风暴 (6.86 次/年)、干 旱 $(5.39$ 次/年) 和山洪 (2.48 次/年)。 20 世纪 90 年代以来, 广布型灾害的年均发
生数超过 400。受 2004 年印度洋海啸影响, 区级广布型灾害记录在 2004-2005 年呈现 急剧增长, 约为正常年份的 5 倍。总体来 看, 泰米尔纳德邦由于处于全球气象灾害 脆弱区, 其气象灾害类型多且影响显著。

\section{4. 广布型灾害影响}

\section{1 人员伤亡}

在泰米尔纳德邦, 广布型灾害造成的 人员死亡占自然灾害总死亡人数的 $39.46 \%$, 其中, 暴雨、洪水、闪电和电风暴等灾害 是主要的致死原因。山洪是造成人员受伤 的主要灾种 (占比 $59.09 \%$ ), 气旋造成 $93.56 \%$ 的人员失踪, 洪水是影响范围最广 的灾种, 受灾人数占比 $100 \%$, 受影响人数 占比 $95.40 \%$, 疏散人数占比 $68.37 \%$ 。从时 间上看, 广布型灾害致人死亡的数量呈增 加态势, 除 2004-2005 年极端灾害期间, 二十多年来广布型灾害导致的年均死亡数 达 100 人。 


\section{af anturs}

广布型灾害致死人数广泛地分布于泰 米尔纳德邦的各个县、区 (图 3-a), 其中, 古达罗尔县 (T18) 的吉登伯勒姆区因灾死 亡 168 人, 占比 $9.90 \%$, 金奈县 (T02) 的 金奈区因灾死亡 109 人, 占比 $6.45 \%$ 。因灾 受损人数主要集中在杜蒂戈林县 (T28) 的 蒂鲁琴杜尔区 (1106 人, 占比 $52.94 \%)$ 、 德尼县 (T25) 的乌塔马帕拉耶姆 (253 人) 和金奈县 ( T02) 的金奈区 (106 人) (图 3-b)
应。

古达罗尔县 (T18) 的吉登伯勒姆区是 暴雨和洪水灾害物理破坏的重灾区 (图 4a.b)，毁坏房屋 3.55 万间 (占比 $40.71 \%$ )， 受损房屋 5.88 万间 (占比 $10.78 \%$ )。其他 房屋受损严重的地区包括：蒂鲁伯蒂县 (T01) 的安巴杜尔区 (8.00 万间, 占比 $14.66 \%)$ 、金奈县 $(\mathrm{T} 02)$ 的金奈区 $(7.72$ 万间, 占比 $14.15 \%)$ 和坎契浦兰县 (T03) 的塔姆巴拉姆区 (6.58 万间, 占比

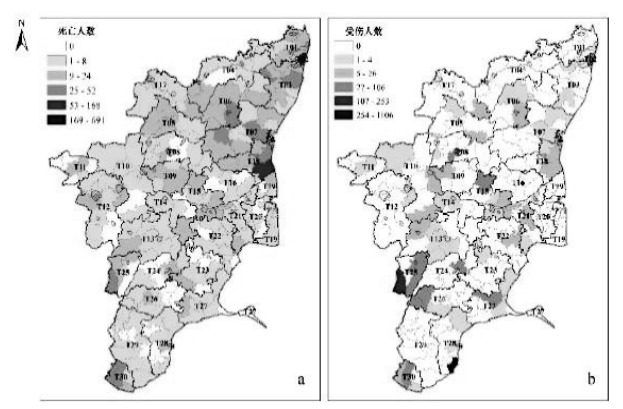

图 3 广布型灾害致人伤亡空间分布
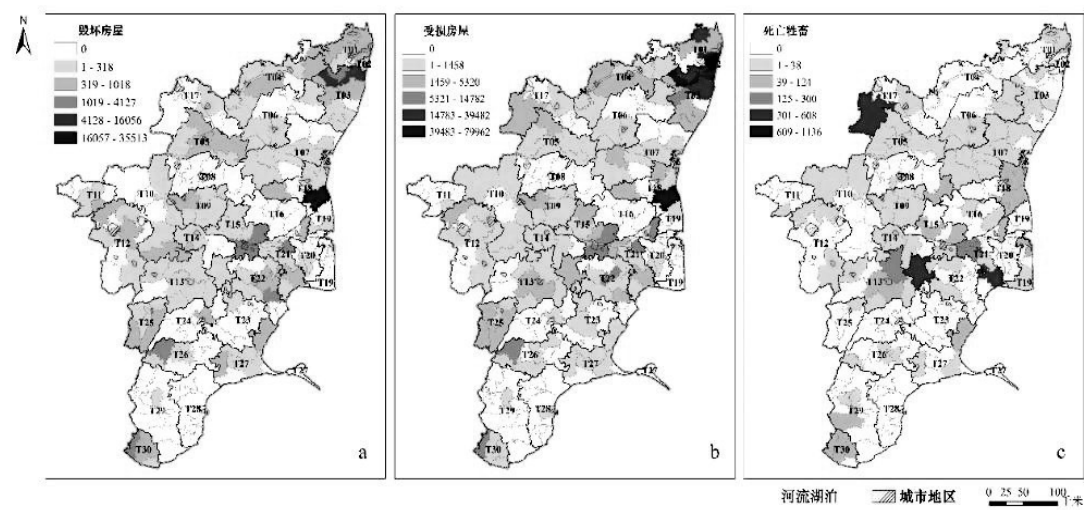

图 4 广布型灾害造成物理破坏的空间分布

\section{2 资产破坏}

1968-2011 年间, 泰米尔纳德邦各类广 布型灾害共造成房屋毁坏 10.33 万间（占 比 $35.20 \%$ )、房屋受损 61.64 万间（占比 $61.10 \%$ ), 农作物受损 183.87 万公顷（占 比 $81.97 \%$ ), 牲畜死亡 5473 只 (占比 $66.96 \%$ ), 道路受损 13626 千米 (占比 95. 00\%)。洪水和暴雨是造成研究区资产物 理破坏的主要致灾因子, 海啸、山洪和气 旋在不同层面上加剧了灾害的物理破坏效
$12.06 \%)$ 。因灾死亡的牲畜主要分布在蒂鲁 吉拉伯利县 (T15) 的默讷巴赖区、可瑞什 纳吉丽县 (T17) 的登卡尼科泰区和坦加布 尔县 (T21) 的佩拉武拉尼区 (图 4-c)。

\section{3 经济损失}

1968-2011 年间, 泰米尔纳德邦广布型 灾害造成直接经济损失 24.75 亿卢比, 基 础设施经济损失 65.03 亿卢比, 农业经济 损失 73.63 亿卢比。广布型灾害造成的直 接经济损失占自然灾害损失的 $85.35 \%$, 基 
础设施和农业间接损失分别占比 $59.47 \%$ 和 $61.44 \%$ 。具体灾种方面, 洪水是主要的致 损原因，直接经济损失占广布型灾害损失 的 $73.74 \%$, 基础设施和农业间接损失分别 占比 $74.03 \%$ 和 $68.37 \%$ 。其次是暴雨、气旋 和海啸灾害。此外, 干旱是造成农业间接 损失不可忽视的因子。

广布型灾害造成的各类经济损失在空 间上呈现相似的分布特征 (图 5), 这一点 从相关系数 (均 >0.7, 通过 $99 \%$ 置信度水平) 也可得到印证。具体而言, 直接经济损失 分布在吉登伯勒姆区 ( T18 县, 占比 $20.88 \%$ )、古德洛尔区 ( T18 县, 占比 $17.34 \%)$ 、塔姆巴拉姆区 ( T03 县, 占比 9. $08 \%)$ 和古米迪波奥恩迪区 ( T01 县, 占 比 $4.65 \%$ ); 基础设施和农业损失主要分布 在吉登伯勒姆区（T18 县）、塔姆巴拉姆区 (T18 县)、安巴杜尔区 (T01 县) 和金奈 区 (T02 县)。
农村贫困地区、城市非正式住宅区）的特 定灾害受体 (如穷人、妇女、老人和儿童) 而言, 广布型灾害风险的潜在效应或间接 影响 (如贫困、不平等、发展受阻等) 更 加值得关注, 也是本领域进一步研究的重 要主题。

\section{Acknowledgements}

This work was financially supported by Program for the Philosophy and Social Sciences Research of Higher Learning Institutions of Shanxi (PSSR, No. 2017314), Program for the soft science of Shanxi Province (No. 2017041025-2).

\section{致谢}

本研究得到了山西省高等学校哲学社会科 学研究项目 (2017314), 山西软科学研究 项目 (2017041025-2) 的资助。

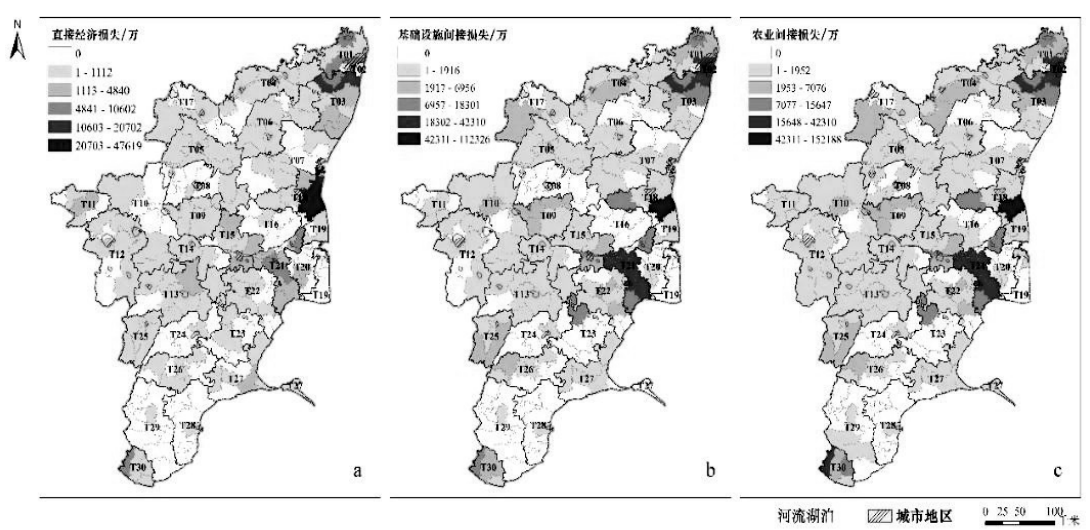

图 5 广布型灾害导致经济损失的空间分布

\section{5. 结论与讨论}

总的来说, 广布型灾害的直接影响包 括人员伤亡、资产破坏和经济损失。与密 集型灾害相比, 广布型灾害的记录数超过 总灾害数的九成, 死亡人数近四成、受伤 人数约五成, 房屋毁坏超四成、房屋受损 超六成、农作物破坏超八成、道路损坏超 九成, 直接经济损失超过八成、间接经济 损失约六成。换句话说, 广布型灾害风险 是真正且持续威胁人类日常生存和长期发 展的潜在因素。此外, 对于特殊地区 (如

\section{参考文献}

[1] UNISDR. 2007. Disaster Risk Reduction: 2007 Global Review [EB/OL]. Prepared for the Global Platform for Disaster Risk Reduction First session, Geneva, Switzerland.

http://www.preventionweb.net/globalplatf orm/2007/first-

session/docs/session_docs/ISDR_GP_200 7_3.pdf.

[2] UNISDR. 2009. Risk and poverty in a changing climate $[\mathrm{EB} / \mathrm{OL}]$. Global 
Assessment Report on Disaster Risk Reduction (GAR 2009). http://www.preventionweb.net/english/hy ogo/gar/2009/?pid:34\&pif:3.

[3] United Nations. 2016. Report of the open-ended intergovernmental expert working group on indicators and terminology relating to disaster risk reduction $\quad(\mathrm{A} / 71 / 644) \quad[\mathrm{EB} / \mathrm{OL}]$. http://www.preventionweb.net/files/5068 3_oiewgreportenglish.pdf.
[4] Xue Y, Li X X, Su W, et al. A fuzzy method for assessing eco-environmental disaster risk caused by coalbed methane in China. Journal of Risk Analysis and Crisis Response, 2018, 8 (1): 3-13.

[5] UNISDR. 2015. Making Development Sustainable: The Future of Disaster Risk Management [EB/OL]. Global Assessment Report on Disaster Risk Reduction (GAR 2015). http://www. preventionweb.net/english/hyogo/gar/201 5/en/home/index.html. 